\title{
La tenencia de la tierra en el mundo bolivariano
}

Lucía Sala de Tourón Ana Carolina Ibarra

FFyL-UNAM

Se analizan, a través de algunos decretos, los aspectos más relevantes de la política agraria impulsada por Bolívar.

$\mathrm{G}$ 1 proyecto bolivariano de organización estatal, en un ámbito más extenso del que finalmente plasmó en cada uno de los países hispanoamericanos, de integración de los "americanos del sur", ha sido de tanta importancia, que ha opacado otros aspectos significativos de la política del Libertador. Es importante, sin embargo,considerar algunos temas relacionados conlas transformaciones o permanencias de elementos estructurales y que incidieron deforma decisiva incluso en el fracaso de su proyecto político.

Sin duda, en Hispanoamérica no existían ni los requisitos materiales ni los ideológicos para la conformación de un solo estado que pudiese abarcar al con- junto de las ex colonias al finalizar las luchas por la independencia. No se habían generado durante el coloniaje ni plasmado durante las guerras, lo cual no hace menos importantes los proyectos que, junto al fundamental bolivariano, se trazaron antes y después, propugnando por la integración hispanoamericana o latinoamericana. Sería muy útil estudiar, con mayor cuidado de lo que se ha hecho hasta ahora, las causas reales de su frustración y de la tendencia centrífuga que plasmó en el nacimiento de los nuevos estados.

Pero no es un tema tan amplio el que abordamos en este trabajo. Haremos unas cuantas observaciones sobre algunos aspectos de las relaciones so- 
ciales que predominaron en el contexto hispanoamericano y que se convirtieron en limitaciones de los estados nacionales y en qué medida Bolivar intentó destruirlas al proponer una serie de medidas para propiciar cierta modernización de la economía.

Las más importantes en este rubro fueron la supresión de la esclavitud (nunca ratificada por las asambleas), la eliminación del tributo indígena (restablecido al resultar ineficiente la tributación sustitutiva), el intento de barrer las formas precapitalistas de renta en trabajo, en especial su sustitución por el salario para la minería, obrajes y haciendas, la devolución de tierras a las comunidades indígenas y la eliminación de la posesión comunal, de hecho también inaplicadas, etcétera.

En conjunto debían contribuir a imponer como dominante el modo de producción capitalista en un lapso más rápido que aquél en que cuajó este proceso en América Latina. Se trataba de cumplir algunas tareas burguesas: liberar a la fuerza de trabajo, contribuir a la conformación del mercado interno, etc. Pero era demasiado sólido el sistema preexistente. Las guerras por la independencia y las luchas entre bandos produjeron un fuerte consumo y destrucción de riqueza y de fuerzas productivas incluyendo la fuerza de trabajo. Las protoclases burguesas (básicamente burguesía comercial y la limitadamente ligada a procesos productivos) eran demasiado débiles; orientaron sus escasos capitales al comercio exterior y la usura y debieron competir desventajosamente con el capital comercial y usurario británico y de otros países extranjeros desde las primeras etapas de las luchas por la independencia. No se habían conformado, ni se conformaron entonces, clases "estrictamente nacionales, incluso a nivel de los espacios estatales más limitados que finalmente plasmaron.

En las clases que emergieron de la independencia como dominantes (incapaces, por otra parte, de articularse para imponer un poder sólido durante varias décadas) una mentalidad comarcana, regional, local. Desplazado el segmento español de la oligarquía colonial, los más importantes fueron los sectores importadores y exportadores, una especie de burguesía compradora, cuya esfera de acción se vio limitada por el capital comercial extranjero. Los negocios con un Estado muy débil fueron disputados por verdaderos clanes de usureros, cuya acumulación de capital tuvo un fuerte tono especulativo. La consolidación de la propiedad de la tierra demoró décadas, y en torno a ella disputaron las inorgánicas clases dominantes de las capitales con las regionales y entre fracciones locales aglutinadas alrededor de caudillos. El Estado no estaba realmente segregado de una sociedad civil estructurada, de manera precapitalista, en torno a los terratenientes dueños efectivos del poder local.

La consolidación de los Estados que surgieron en Hispanoamérica fue más tardía, apenas a partir de las décadas finales del siglo XIX. El estado oligárquico estaba sustentado en el predominio de una oligarquía mercantil-terrateniente en la que operaron como núcleo de poder económico y político los segmentos que producían o traficaban con el mercado exterior, fuertemente articulados con el capital extranjero que siguió dominando el gran comercio y que fue invertido en la banca, los servicios públicos y hasta en limitadas actividades productivas y adelantó empréstitos que, entre otras cosas, se utilizaron en la creación de los aparatos militar, administrativo, etc. del Estado. 


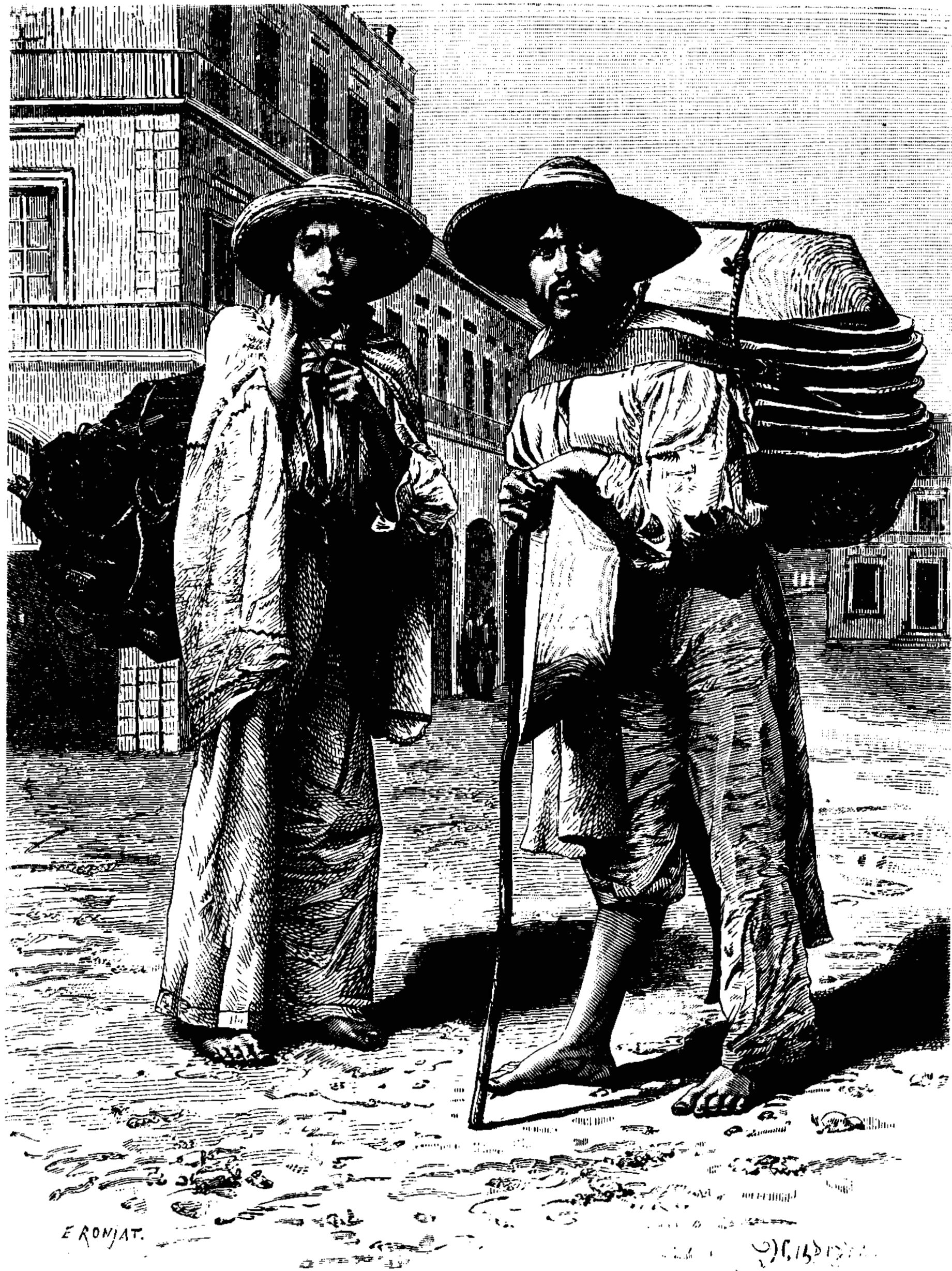


Con anterioridad, salvo casos muy excepcionales, el aparato estatal fue muy débil, las clases dominantes pugnaban por constituirse y se enfrentaban por la apropiación del excedente de los medios de producción; y es que coexistía con un proceso de acumulación originaria, que se transformaría en dominante sobre formas de apropiación y "redistribución precapitalistas, en la segunda mitad del siglo XIX. Continuaron como dominantes, aunque en retroceso, relaciones esclavistas y de tipo servil, colonato, aparcerías, renta en trabajo y especie, etcétera.

Este aparato estatal débil era, sin embargo, instrumento esencial para la apropiación del excedente y los medios de producción.

\section{LA TIERRA}

Si la explotación minera había sido el eje de la articulación de espacios económi$\cos$, a su servicio había estado una amplia producción agraria durantela época colonial. Sin que la minería perdiera su significación, la destrucción de circuitos comerciales internos, ya en algunos casos desvertebrados parcialmente en el periodo borbónico, se acentuó ahora decididamente. Por múltiples razones la economía se ruralizó y, durante un tiempo en gran parte del ex imperio colonial español decayó el tráfico, la circulación de mercancías y la monetaria.

Perviven haciendas cuya producción no supera al mercado local o, básicamente, de autoconsumo, comunidades indígenas con escasa vinculación al mercado, etc. Sin que cesara nunca el despojo de los indígenas, el asalto a sus tierras no tiene la virulencia que revestirá en las décadas finales del siglo.

Es entonces cuando, junto a la consolidación jurídica de la propiedad, se seculariza la propiedad eclesiástica y se reducen las tierras en poder de los indígenas de manera drástica, cuando se limita la pequeña posesión campesina. Es bien conocida la relación de este fenómeno con una más estrecha inserción en el mercado mundial y el que la consolidación de la propiedad fuera paralela a la imposición del capitalismo en el campo por la vía reaccionaria o latifundista. El latifundio se afirmó y sobre esta base persistieron relaciones precapitalistas articuladas al modo de producción capitalista dominante.

En las décadas anteriores perviven en poder de la Iglesia enormes extensiones no ocupadas, poseídas por comunidades indígenas y campesinos mestizos. La fuerza de trabajo no carece totalmente de medios de producción. Debe ser compelida al trabajo en las haciendas por un Estado que suele delegar esta función en los hacendados.

Son también conocidas las modalidades mediante las cuales bajo el coloniaje se produjo la apropiación de la tierra, cuyo proceso se acentuó notablemente en el periodo borbónico.

Durante las luchas por la independencia, con mayor o menor intensidad, se produjo la transferencia de las tierras de determinados propietarios y poseedores a otros. Sin duda este fenómeno fue menos importante cuantitativamente que el debienes muebles fácilmente confiscables y con gran parte de los cuales se financiaron las propias guerras, y que incluso fueron trasladados a Europa por los españoles que emigraron entonces. El pillaje y el saqueo, los empréstitos voluntarios o forzados, etc. provocaron en mayor o menor grado un empobrecimiento bastante extendido. Se ha demostrado de manera fehaciente, que en Venezuela el pillaje fue la forma de satisfacer a las fuerzas que acompaña- 


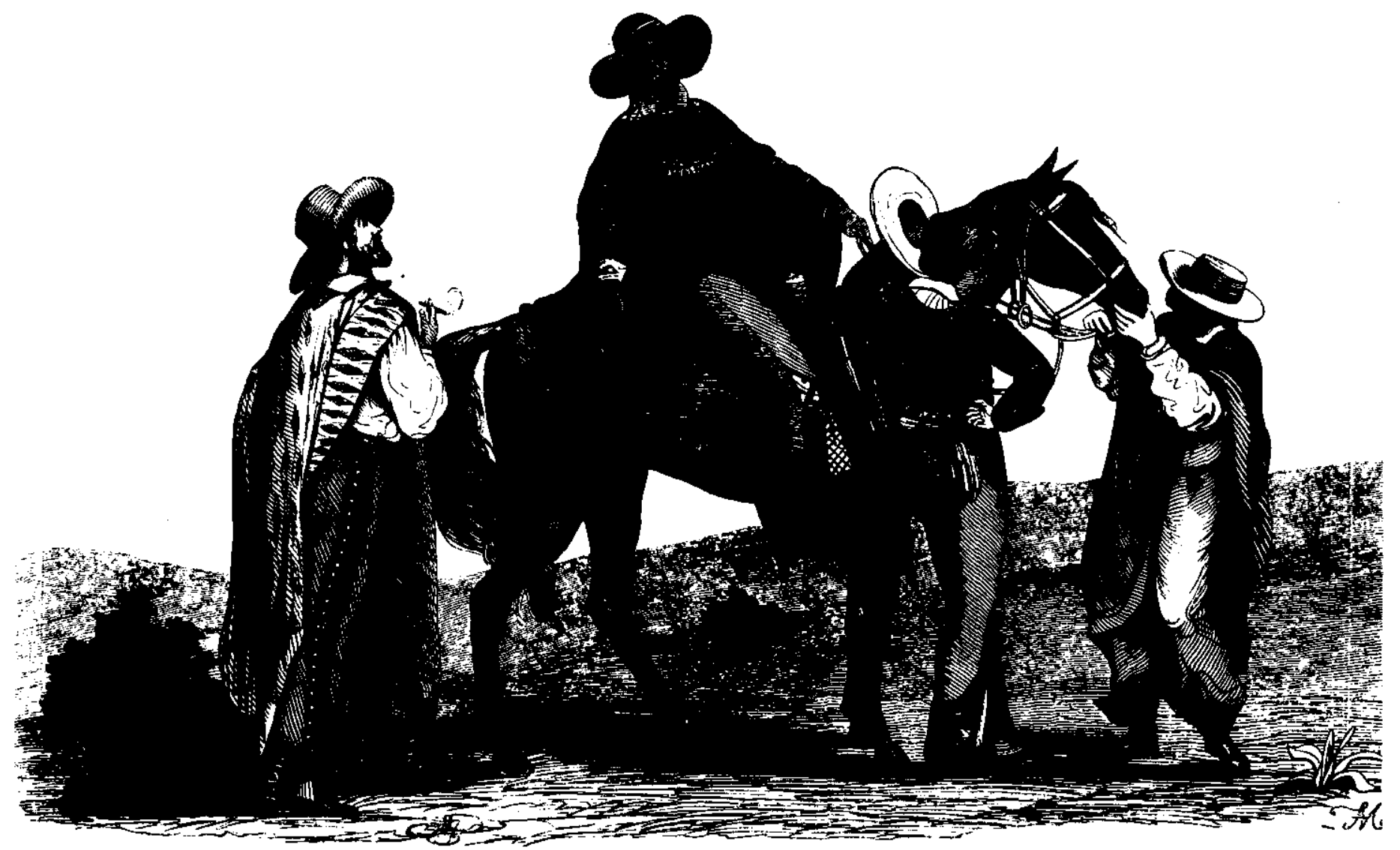

ban a los caudillos españoles en las etapas iniciales, y no sólo a éstos, el hecho puede extenderse al conjunto de la Hispanoamérica insurgida en mayor o menor grado.

Pero esta transferencia incluso la de la propiedad urbana, no afectó la estructura básica de la sociedad. En lo fundamental tampoco sucedería esto con el traspaso de la tierra dedicada al cultivo o a la ganadería. Existieron proyectos que suponían una transformación de la estructura agraria como el discutido plan encontrado en Cuautla, el "Reglamento para fomento de la campaña y seguridad de sus hacendados", dictado para la Provincia Oriental en 1815 , y no pocas otras disposiciones de carácter regional o local. En ellos se disponía la fractura de la propiedad latifundista, por lo menos la de los enemigos de la revolución. Aun allí donde tuvieron ejecución, como su- cedió con el reglamento artiguista, sus títulos iban a ser luego desconocidos por los gobiernos independientes y de hecho significaron una valla, no insalvable pero sí real, para la imposición del capitalismo en el campo por la llamada vía junker o reaccionaria que acabó primando a fines del siglo XIX. Pero lo característico fue el traspaso de una parte de la tierra a viejos y nuevos hacendados criollos -entre los que se contaba un porcentaje significativo de los oficiales, incluso quienes habían peleado en el bando español y pasado al criollo en las etapas finales de las luchas- comerciantes, abastecedores, usureros, etc., que adquirieron sus derechos a oficiales o soldados o vieron satisfechos con tierras sus créditos contra los nuevos estados. Alli donde en consecuencia se produjo la transferencia de la tierra, no se determinó un cambio de gravitación significativa en el sistema 
mismo de tenencia, lo que incidió decisivamente en la estructuración de un sistema de poder caudillista.

\section{LAS MEDIDAS BOLIVARIANAS}

El hecho de que Bolívar no haya planteado un proyecto orgánico de destrucción del latifundio, ni haya hecho explícito un proyecto global sobre las modificaciones que en su concepto debían realizarse para modernizar la estructura agraria de la Gran Colombia, ha dado lugar a un sinnúmero de interpretaciones polémicas y contradictorias entre sí. Decretos como aquellos que emitió en torno al pago de los oficiales y soldados que habían participado en la contienda tuvieron indudablemente motivaciones fiscales, sin embargo, también es cierto que de haberse aplicado con rigor hubieran contribuido a crear una capa más amplia de pequeños y medianos hacendados. Es cierto también que la ruptura de la propiedad comunal habría coadyuvado al desarrollo capitalista, a condición de que el conjunto de la estructura social se modificara en este mismo sentido.

Las diversas medidas dictadas bajo diferentes circunstancias, cuya trayectoria es modificada a su vez por las innumerables presiones e intereses que intervienen en el curso de los acontecimientos de la posindependencia, nos obligan no sólo a precisar el contenido y circunstancias bajo las cuales surgen éstas, sino también a intentar aproximarnos a una apreciación sobre las motivaciones que subyacen a las determinaciones del Libertador. Que un cambio profundo en la estructura socioeconómica en el sentido del desarrollo capitalista parece haber sido la intención del proyecto bolivariano, es algo que sólo puede apreciarse al recoger algunos elementos fundamentales de su discurso y rastrear la trayectoria, no sólo de las medidas relativas al problema de la tierra, sino al analizar éstas junto a otras medidas adoptadas y que, de habersido aplicadas cabalmente, hubieran contribuido en su conjunto a modificar profundamente la estructura social preexistente.

A través de la revisión de importantes testimonios y documentos de la época sobre la cuestión agraria en Venezuela, hemos podido trazar algunos de los principales lineamientos de la política bolivariana en la materia e ir apreciando algunos de sus efectos en diversos sectores de la población afectada. Estos elementos nos han permitido distinguir en ella modificaciones sustanciales que marcan periodos bastante definidos: el que va de la "guerra a muerte" (1813-14) hasta 1816 , momento en que la posibilidad del triunfo se supedita a la capacidad que desarrolla el Ejército Republicano para realizar alianzas con sectores más amplios de la población; el periodo que abre en 1816 con la vuelta de Bolivar de su exilio caribeño y que puede considerarse como el más fecundo y creador en cuanto al alcance social de las medidas dictadas. A partir de la instalación del Congreso de Cúcuta (1821-22), sobre las disposiciones previas se irán imponiendo, gradualmente, una serie de ajustes. El Congreso será la sede de las primeras discusiones para limitar el vigor de algunas de las medidas establecidas entre 1816 y 1820.

Al mismo tiempo, la realidad va propiciando una serie de mecanismos que tienden a convertir el proceso de redistribución de la tierra inaugurado por Bolívar con sus leyes y decretos sobre "Haberes militares", en un proceso de transferencia de la tierra, efectivamente, pero cada vez más inclinado a favorecer 
a los altos jefes militares. Son los primeros pasos hacia lo que será el nuevo proceso de concentración de la tierra que alcanzará perfiles exagerados en las décadas posteriores.

Detodos modos, el desenvolvimiento de los hechos en Venezuela, no impide que en la campaña andina Bolívar reavive la política de secuestros como parte de la guerra que se extiende en el sur y se preocupe por sancionar los derechos de los indígenas de las regiones peruanas y altoperuanas.

\section{LOS ANTECEDENTES: "LA GUERRA A MUERTE"}

Con el "Decreto de guerra a muerte", Bolivar intenta redefinir la lucha, polarizando el enfrentamiento entre españoles $\mathrm{y}$ americanos.

La amenaza de una guerra de castas, con grandes masas de pardos y mulatos acaudillados por Boves el jefe llanero, abre un periodo de enorme violencia en la independencia venezolana.

Ha sido muy comentada la particular brutalidad con que Boves procedió y la audacia con que manejó la posibilidad de que su ejército saqueara comarcas y ciudades no sólo resultando retribuido por medio de esta acción, sino utilizándola como incentivo para atraer mayores contingentes a la guerra. Aproximarnos a una explicación seria sobre cuales fueron los factores que contribuyeron a fortalecer las relaciones entre el caudillo y las masas de pardos y llaneros, es un tema que rebasa los marcos de este trabajo. Sin embargo, nos parece importante recordar aquí lo que a propósito de la política inaugurada por Boves en Venezuela, señala Carrera Damas:

El ejercicio del saqueo durante la guerra de emancipación aparece... como la con- tinuidad de tradicionales procedimientos militares, propiciada y agudizada en esta ocasión por factores socioeconómicos estructurales que regían para ambos contendientes con igual fuerza: la penuria fiscal y el desquiciamiento de la vida económica; la rarificación del numerario...(etcétera.) $)^{1}$

En diciembre de 1813, Bolívar estableció las primeras normas para proceder en los casos de secuestro y al año siguiente se pusieron en venta y subasta pública los bienes de españoles y canarios. Más tarde se exceptuarían "como un rasgo de la generosidad americana", las confiscaciones de los bienes correspondientes a herencias y a dotes de hijas casaderas de los enemigos, cobrando el Estado la quinta parte como multa.

\section{LA CREACIÓN DE UN EJÉRCITO POPULAR Y LA POSIBILIDAD DE CONFORMAR MASAS "LIBRES"}

La lucha por la independencia, retomada por el Ejército Republicano en 1816, significó el establecimiento de compromisos con sectores más vastos de la población. La muerte de Boves y el autoritarismo de las fuerzas restauradoras acaudilladas por Pablo Morillo, facilitaron que contingentes de esclavos, pardos y llaneros que antes lucharon por la causa realista, pasaran a las filas de la revolución. El avance de la guerra y la imperiosa necesidad de dar un combate de mayores proporciones, determinaron el desarrollo y fortalecimiento de un ejército cuya composición se modificó por la incorporación de nuevos elementos. La política de atracción hacia los

${ }^{1}$ Germán Carrera Damas, Materiales, 1964, vol. l, p. civl.

\section{.}


caudillos regionales jugó un papel determinante en este sentido. ${ }^{2}$

En este lapso en el que Bolívar vuelca lo mejor de sus iniciativas en materia de democratización agraria, serán dictadas una serie de disposiciones que, de haber sido aplicadas, indudablemente habrian producido cambios sustanciales en la estructura económica y social venezolana. El decreto de Angostura del 10 de octubre de 1817 sobre el reparto de los bienes secuestrados entre los militares del Ejército Republicano; los decretos del 11 de marzo de 1818 y 22 de enero de 1820 sobre la libertad de esclavos y el decreto del 20 de mayo de 1820 para restablecer los derechos de los indígenas, expresan en conjunto su concepción sobre lo que serían el tipo de relaciones de propiedad y trabajo sobre las cuales se basaría la formación del nuevo Estado.

El problema de retribuir a los militares por sus servicios se presenta como una de las necesidades prioritarias en esta etapa. El Decreto de Angostura, del 17 de octubre de 1817 colocó como primer deber del gobierno el reparto entre los militares del Ejército Republicano de los bienes secuestrados al enemigo. Este documento estableció un reparto proporcional, en función del grado del militar de que se tratase. Las cantidades asignadas iban de 500 pesos para el soldado raso, a 2500 para el general en jefe. Preveía también la posibilidad de otorgar asignaciones extraordinarias como premio a los servidores más destacados. No se fijó límite alguno sobre el monto de dichas asignaciones, pero decretos posteriores muestran que éstas rebasaron con creces las cantidades previstas para los militares de más alto rango. Entre 1820 y 1822 vemos convertirse a los prin-

\footnotetext{
${ }^{2}$ Miguel Acosta Saines, Bolivar, 1982.
}

cipales jefes de la revolución en flamantes propietarios de hatos de ganado muy codiciados en Colombia y Venezuela. ${ }^{3}$

Bajo los mismos términos del decreto de 1817 , el 6 de enero de 1820 el soberano Congreso sancionó la Ley sobre reparticiones de bienes nacionales entre los servidores de la patria que reiteró el mismo discurso

...atendiendo a las privaciones a que han sujetado todos los servidores de la patria, sacrificios que han hecho, peligros a que se han expuesto, decreta lo siguiente: todos los bienes nacionales... se repartirán entre los servidores de la patria... ${ }^{4}$

Durante esta etapa, la lucha se convirtió también en un elemento que, en tanto tuvo capacidad de absorber contingentes masivos, comprometió a la estructura productiva preexistente. Las nuevas exigencias sitúan a la milicia como la vía más expedita de liberar a un buen número de esclavos dispuestos a abrazar las armas.

Abolida la esclavitud por el Libertador en un decreto nunca después ratificado en los términos de su formulación original, Bolivar dirigió una invitación a "todos los que antes eran esclavos" a formar batallones para defender su libertad. ${ }^{5}$ Las quejas ante tal medida, manifestadas por los propietarios de las plantaciones en una serie de artículos y comentarios reproducidos en la prensa de la época,

${ }^{3}$ En estos años fueron premiados Santander, Páez, Briseño, Mariño, Nariño, Bermúdez, Soublette, Arizmendi y otros. La documentación respectiva muestra cómo el gobierno puso por encima este interés, el de favorecer a los compradores que hicieron importantes ofertas sobre las haciendas. Uno de los ejemplos más ilustrativos es la asignación de la hacienda La Trinidad a José Antonio Páez.

${ }^{4}$ Carrera, op. cit., p. 263.

${ }^{5}$ Ibid., pp. 213-214 ("Decreto del 11 de marzo de $\left.1818^{\prime \prime}\right)$. 
no sólo sirven para ilustrar la fuerza de los intereses que se afectaban con ella, también constituyen un elemento esencial para explicar su posterior retroceso.

\section{TRIUNFO DE LA REVOLUCIÓN Y REESTABLECIMIENTO DE UN NUEVO ORDEN}

En un elocuente documento, el 22 de enero de 1820 el Congreso de Cúcuta emitió un decreto inicial sobre la cuestión de la esclavitud en los siguientes términos:

Es preciso en el estado de ignorancia y degradación moral a que esta porción desgraciada de la humanidad se halla reducida, es preciso en tal estado hacer hombres antes de hacer ciudadanos... El Congreso, considerando la libertad como la luz del alma, creyó también que debía dárseles por grados como a los que recobran la vista corporal, que no se les expone de repente a todo el esplendor del día...

Con vistas a la elaboración de un plan "preciso y justo" que "gradualmente" fuera liberando a los esclavos, el Congreso posponía en aquella ocasión sus determinaciones sobre dicha cuestión. En ese año de 1820 se limitó exclusivamente a garantizarles a los antiguos esclavos que habían ganado su libertad que seguirían disfrutando de esta nueva condición, mientras pronunciaba las primeras líneas de un discurso que indudablemente tendía a justificar políticas posteriores.

El 19 de julio de 1821, la Ley sobre libertad de partos, manumisión y abolición del trafico de esclavos retomaba

${ }^{6}$ Ibid., p. 266 ("Decreto sobre la libertad de esclavos"). la cuestión con las siguientes determinaciones: se declaraban libres los hijos de esclavas nacidos a partir del momento de la publicación de la ley; los dueños de las esclavas se harían cargo de su alimento, educación y vivienda en pago de lo cual éstos trabajarían para ellos hasta los 18 años. La única posibilidad de que consiguieran liberarse antes del plazo marcado era a través de la indemnización correspondiente para la manumisión.

En 1830, la Ley de manumisión significó un retroceso respecto a la Ley de libertad de vientres de 1821 , puesto que elevó a los 21 años la edad para la manumisión. No sería sino hasta el 24 de marzo de 1854 cuando se declararía abolida para siempre la institución y precisamente cuando la esclavitud habría dejado de ser rentable para los propietarios pues iban cobrando mayor importancia otras formas de explotación del trabajo como el peonaje, el arrendamiento de la tierra, etcétera.

Así como una revisión de la evolución dela esclavitud en Venezuela muestra de manera evidente los cambios que fueron sufriendo las medidas originales emitidas por Bolívar, los problemas planteados por la situación de las poblacionesindígenas y el destino de las medidas tendientes a la retribución de haberes militares confirman las dificultades que pusieron coto al proyecto inicial del Libertador. Estas dificultades sólo pueden comprenderse en función de los intereses de las clases y los sectores de clase que surgieron al triunfo de la revolución y cuya falta de fuerza se expresa en las intensas luchas que caracterizan el periodo, y que pusieron de manifiesto la inviabilidad de proyectos estatales modernos como el que en su caso deseaba implantar Bolívar.

Emitido en Rosario de Cúcuta el 20 de mayo de 1820, el Decreto del Libertador 

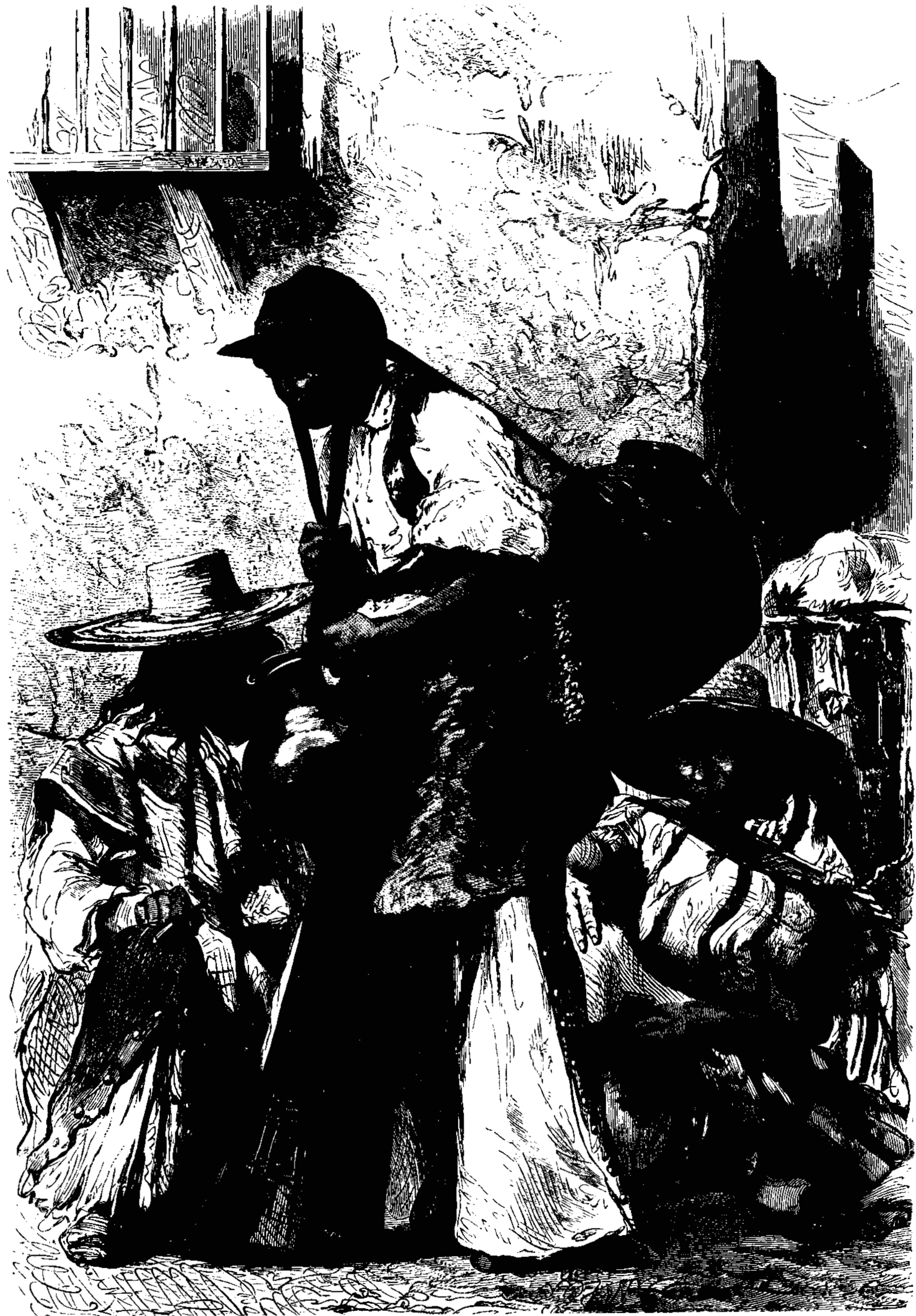
or

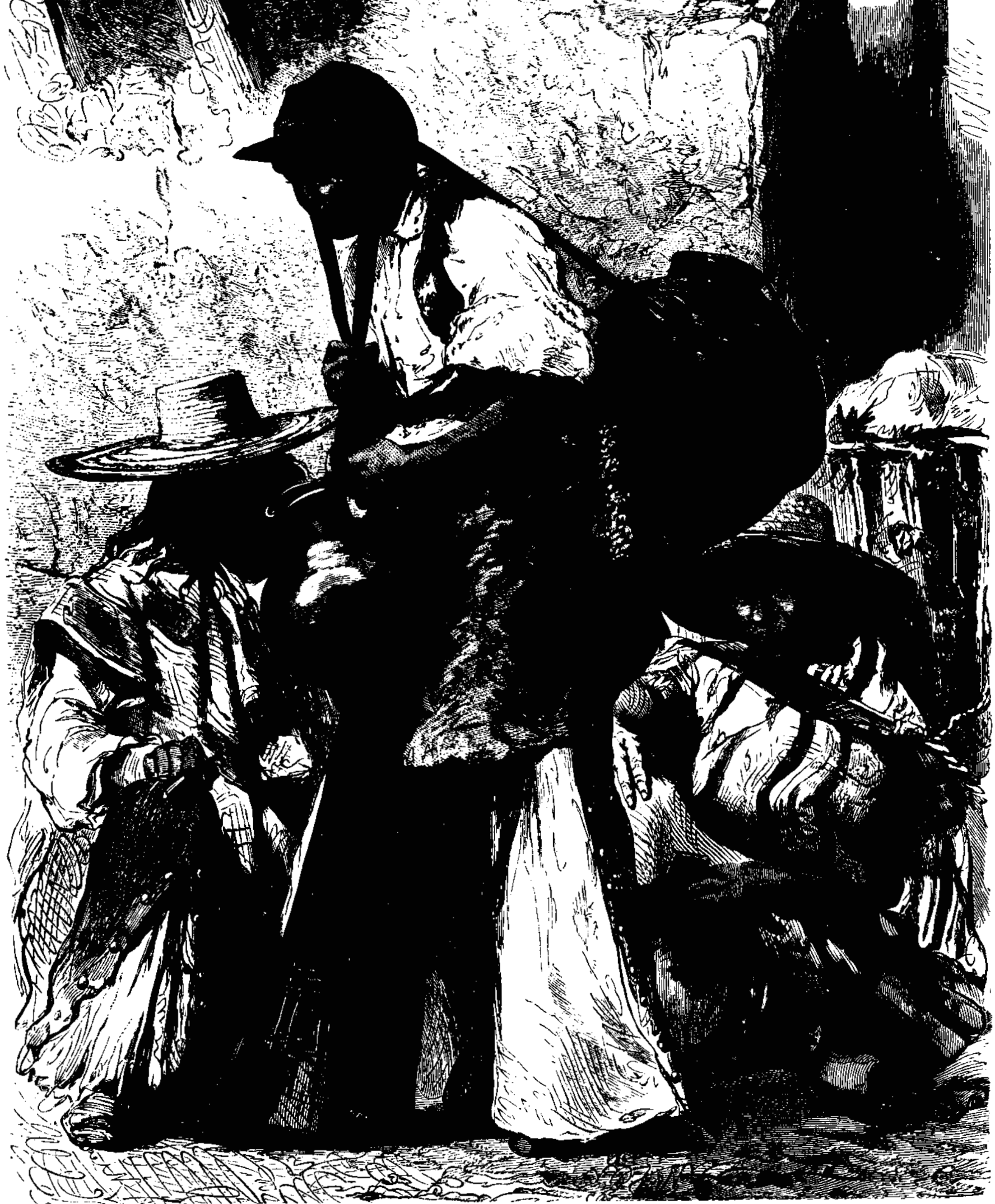


para restablecer los derechos de los indígenas y fomentar su progreso económico y su educación señalaba que "se devolverá a los naturales como propietarios legítimos, todas las tierras que formaban sus resguardos según sus títu$\operatorname{los}{ }^{7}$ Se insistía además en que ni curas ni jueces podrían solicitar servicios de los naturales sin que mediara un contrato.

Ya en oficio dirigido al general Anzoátegui de fecha 1 de julio de 1818, Bolívar había comentado: "no sólo apruebo que se les permita trabajar [a los indios]... [sino que] conozcan que ya son hombres libres y no esclavos como eran en tiempos de los capuchinos".

La ley del 4 de octubre de 1821 sancionó la abolición del tributo indígena, condicionó los servicios al pago de salario y repartió los resguardos, en pleno dominio y propiedad, en la proporción que sirviera para cubrir las necesidades de cada familia indígena. Autorizaba también que la comunidad pusiera en arrendamientolas tierrassobrantes, cuando éstas existieran, y establecía que los fondos obtenidos fuesen utilizados para mantener la escuela y la parroquia.

No pocos abusos e interpretaciones deliberadamente erróneas desvirtuaron la aplicación de la legislación. En los documentos de la época abundan las quejas, incluso de funcionarios oficiales, que muestran cómo el posterior proceso de concentración de la tierra avanzó incluso sobre los resguardos indigenas. Efectivamente, la legislación levantada sobre cimientos precapitalistas tuvo una aplicación dudosa, no obstante lo cual debe ponerse de relieve el alto valor ideológico que posee y su calidad de antecedente de los decretos liberales posteriores. Con este mismo sentido de- ben apreciarse las medidas dispuestas por Bolivar en Perú a través de los decretos de Trujillo y Cuzco, ${ }^{9}$ que abolieron el servicio personal y el tributo indígena y establecieron el reparto de las tierras en propiedad.

A medida que va consolidándose el triunfo colombiano sobre las fuerzas realistas y al ir desplazándose el eje de la gesta militar hacia el territorio peruano, la penuria en que queda la economía da cuenta de los estragos causados por la guerra. Penuria fiscal, escasez de numerario, desquiciamiento de la vida económica, desabasto, falta de brazos en el campo y empobrecimiento del territorio presionan sobre un erario arruinado que tiene frente a sí la tarea de reestructurar un sistema sobre la base de cumplimiento de sus compromisos más apremiantes.

La cantidad de bienes confiscados que permanecieron inactivos, y que el Estado mantuvo "en depósito" para adjudicación, obligaron a buscar compradores los cuales justamente surgieron de las filas de los especuladores, comerciantes y militares enriquecidos en la época de la guerra. No pocos de éstos habían estado inmiscuidos en el negocio originado con la emisión de vales que sirvieron como pago postergado de las tierras prometidas a la tropa que, para resolver sus necesidades más apremiantes, tuvo que venderlos a un precio ínfimo.

Por otra parte, la tendencia a no crear enemistad entre el gobierno y las poblaciones laboriosas fue imponiéndose, procurando mantener respeto y aliento hacia aquellos que aún podían contribuir, aunque sólo fuese en una mínima parte, al funcionamiento de la vida económica. Las nuevas facilidades se concedieron a

\footnotetext{
${ }^{9}$ Simón Bolivar, Doctrina, 1976, pp. 198-202 ("Decretos de 4 de julio de $1825^{\prime}$ ).
}

${ }^{7}$ Ibid., p. 267.

${ }^{8}$ Ibid., p. 214. 
todos aquellos propietarios, incluso españoles, que se adhirieron al gobierno revolucionario y algunos emigrados pudieron volver para hacer ofertas y recuperar sus propiedades.

La política, poco exitosa por cierto, de invitar a extranjeros "de preferencia europeos o norteamericanos" recibió nuevo impulso; para ello, el Estado dispuso de algunos millones de fanegadas en terrenos baldíos que antes le habían sido adjudicados. Para facilitar la compra, se autorizó el pago con vales de deuda consolidada que en su mayoría estaban en manos de los extranjeros.

En 1821, Bolivar autorizó la enajenación de tierras que por alguna razón hubieran vuelto a manos del Estado y, en disposiciones posteriores, se recalcó la necesidad de continuar adjudicando tierras en pago de haberes militares. Esta política llegó a su término hacia 1835 cuando el Estado argumentó que había saldado la mayor parte de sus deudas con los militares. Sin embargo, la prensa de estos años reproduce innumerables quejas de soldados que constituyen un testimonio de protesta ante el proceso de acaparamiento de la tierra que se inaugura en la posindependencia. ${ }^{10}$ No cabe duda que se iniciaba una creciente tendencia hacia la concentración de la tierra que determinaría el posterior fortalecimiento del latifundio. La transferencia de la tierra de manos de un sector expropiado en tiempos de guerra a otro, además de la distribución de tierras baldías y nacionales, efectivamente había intro-

\footnotetext{
${ }^{10}$ Algunas legiones fueron mejor escuchadas, como el ejército de Apure que resultó beneficiado gracias a la mediación de Páez. Otras quejas llegaron demasiado tarde: la legión de Magdalena hizo llegar un pliego a la fracasada Convención de Ocaña, reflejando el descontento que privó entre la tropa al verse engañada.
}

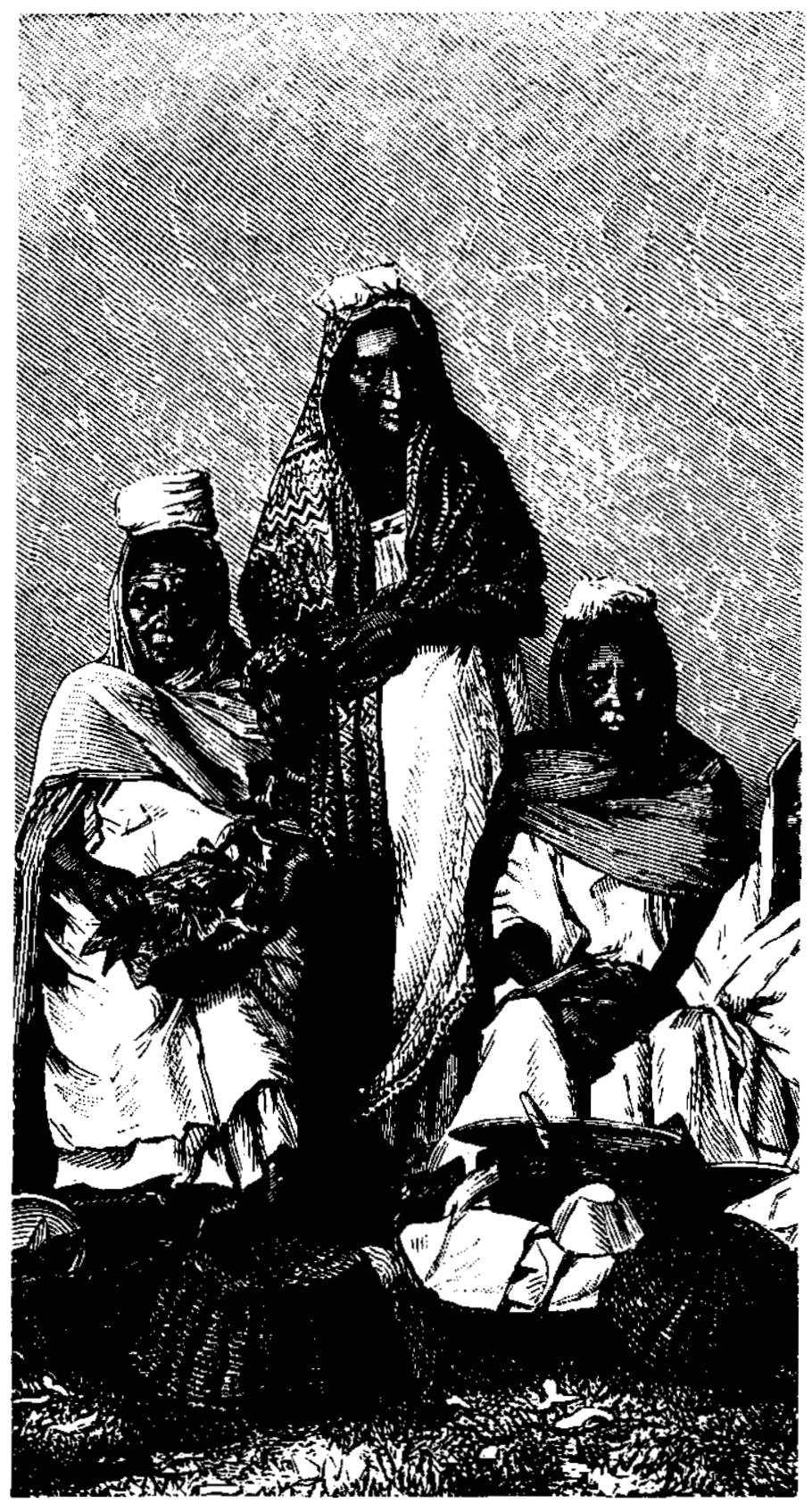

ducido elementos de cambio respecto a la situación anterior, pero, como hemos dicho, no condujo a transformaciones estructurales.

\section{BIBLIOGRAFÍA}

-Carrera Damas, Germán, Materiales para el estudio de la cuestión agraria en Venezuela (1800-1830), Universidad de Venezuela/Consejo de Desarrollo Científico y Humanístico, Caracas, 1964, vol. I.

-Acosta Saines, Miguel, Bolivar acción y utopia del hombre de las dificultades, Universidad Central de Venezuela, Caracas, 1982.

- Bolívar, Simón, Doctrina del libertador, Biblioteca de Ayacucho, Caracas, 1976. 